\title{
Thrombolysis in Acute Stroke Patients with Cerebral Small Vessel Disease
}

\author{
Leonardo Pantoni $^{\mathrm{a}}$ Fabio Fierini $^{\mathrm{b}} \quad$ Anna Poggesi $^{\mathrm{b}}$

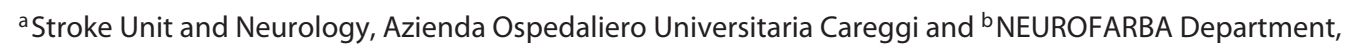 \\ Neuroscience Section, University of Florence, Florence, Italy
}

\section{Key Words}

Small vessel disease - Thrombolysis · Hemorrhages - White matter lesions · Microbleeds

\begin{abstract}
Background: Thrombolytic treatment is of proven benefit in acute ischemic stroke. The term cerebral small vessel disease (SVD) refers to a group of pathological processes affecting the small arteries, arterioles, venules and capillaries of the brain, and encompasses both ischemic and hemorrhagic lesions. Lacunar stroke, an expression of SVD, is associated with an unfavorable long-term prognosis for an increased risk of death, recurrent stroke and cognitive dysfunction. Nonetheless, the efficacy and safety of intravenous thrombolysis in patients with lacunar stroke has been debated for two main reasons. First, among all ischemic stroke subtypes, lacunar strokes have been considered the most benign. Second, the efficacy of a pharmacological reperfusion has been questioned given the absence of a clear demonstration of thrombosis. Intracerebral hemorrhage (ICH) remains the most devastating and unpredictable complication related to thrombolysis, and neuroimaging evidence of SVD is nowadays recognized as one of the risk factors for thrombolysisrelated ICH. Summary: This review is structured in two parts dealing with the questions whether or not patients with lacunar stroke or SVD should be treated with thrombolysis. In the first part, we revised the literature concerning the efficacy of thrombolysis in patients with acute lacunar stroke. We included two types of studies: those in which patients
\end{abstract}

\section{KARGER}

E-Mail karger@karger.com

www.karger.com/ced with lacunar stroke receiving recombinant human tissue plasminogen activator (rt-PA) were compared with lacunar stroke patients receiving placebo, and those in which a comparison was made among different stroke subtype patients treated with rt-PA. In the second part, we reviewed the available evidence on the risk of $\mathrm{ICH}$ in patients treated with thrombolysis for ischemic stroke and presenting with neuroimaging evidence of SVD such as white matter lesions (WML) and cerebral microbleeds. We further questioned the extent to which WML and microbleeds could be used as reliable predictors of $\mathrm{ICH}$ and the feasibility of their detection in an acute setting. Key Messages: The studies herein reviewed show that thrombolysis is an effective treatment in acute lacunar stroke, and that the presence of cerebral SVD increases the risk of ICH during thrombolysis but does not represent an absolute exclusion criterion. In the future, it can be assumed that the use of MRI on a routine basis might lead to a better quantitative definition of SVD and its correlates, permitting a step forward in thrombolysis decision making.

(c) 2013 S. Karger AG, Basel

\section{Introduction}

Cerebral small vessel diseases (SVD) are a group of pathological processes with various etiologies that affect the small arteries, arterioles, venules and capillaries of the brain. In this context, age-/hypertension-related SVD and cerebral amyloid angiopathy are the most common forms. The consequences of SVD on the brain parenchy- (c) 2013 S. Karger AG, Basel

1015-9770/13/0371-0005\$38.00/0 
Fig. 1. Neuroimaging in acute lacunar stroke. a Baseline CT scan of a 75-year-old man affected by slight left ataxic hemiparesis persisting beyond $24 \mathrm{~h}$ (NIHSS score 4 ) and not eligible for intravenous thrombolysis (onset of symptoms $48 \mathrm{~h}$ before hospital admission). b DWI MRI showing a bright hyperintense area of restricted diffusion (arrow). c FLAIR MRI showing a lacunar infarct (arrow) located in the posterior limb of the right internal capsule. At discharge, the patient presented mild weakness of the left lower limb (NIHSS score 1). d Baseline CT scan of a 55-year-old man experiencing a sudden moderate right hemiparesis associated with slight hypoesthesia from the same side (NIHSS score 5) and receiving intravenous thrombolysis. e Control CT scan showing a strategic lacunar infarct (arrow) located in the posterior limb of the left internal capsule and posterior putamen. MRI was not performed. At discharge, the patient presented mild weakness of the right lower limb (NIHSS score 1).
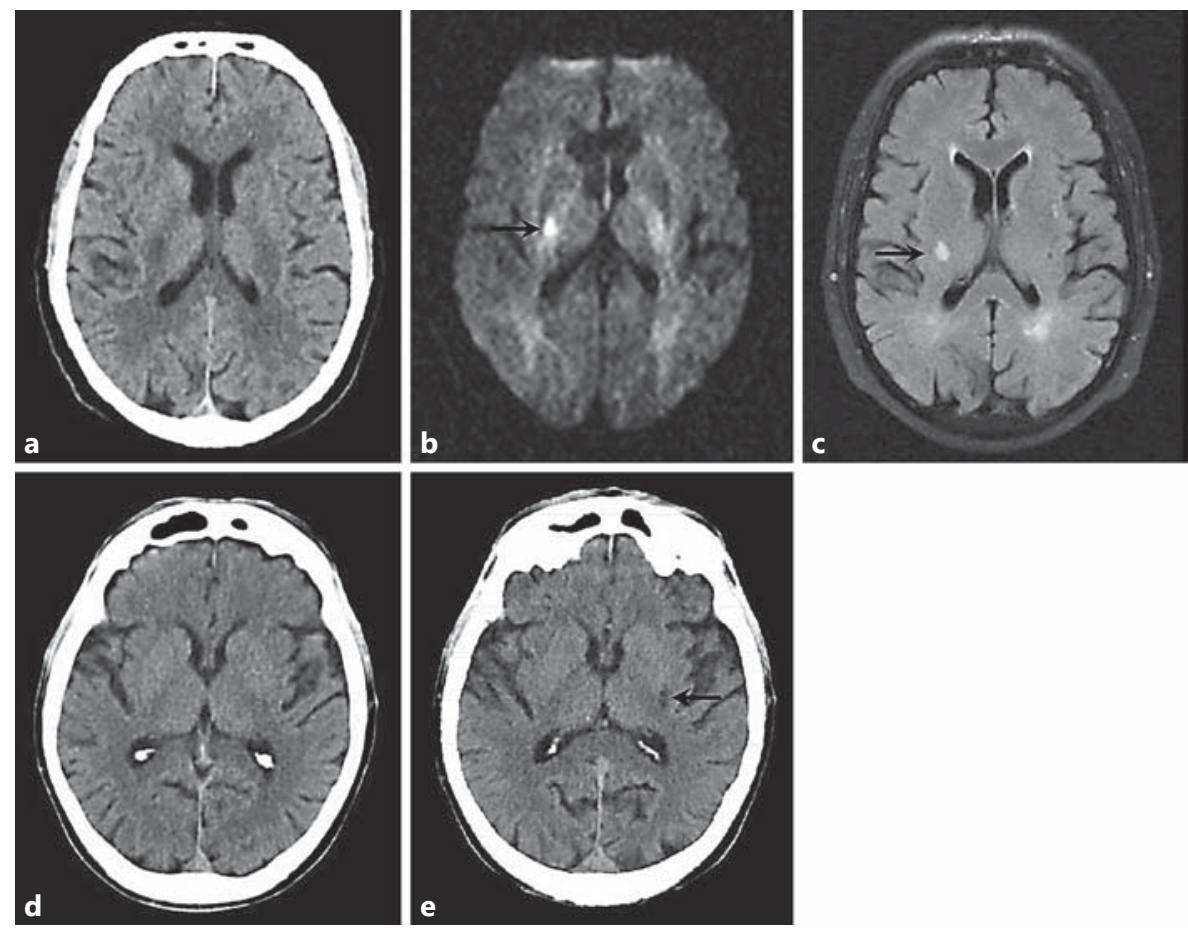

ma can be either ischemic or hemorrhagic, manifesting with lacunar infarcts and white matter changes in the first case, and large hemorrhages and microbleeds in the second [1]. From a clinical point of view, the presence of SVD is related to a risk of cognitive decline, dementia and stroke. Recently, the number of neuroimaging lesions ascribable to SVD has been expanded [2].

The effectiveness and safety of thrombolysis with intravenous recombinant human tissue plasminogen activator (rt-PA) for ischemic stroke have been clearly demonstrated within $4.5 \mathrm{~h}$ of symptom onset [3-5]. However, the possible differences in efficacy of rt-PA and the complication rates among various etiologic ischemic stroke subtypes have not yet been extensively investigated. Intracranial bleeding is the most serious side effect of thrombolysis, and efforts have been made to identify predictors of this occurrence. Current evidence suggests that the presence of SVD on neuroimaging indicates an increased risk of developing symptomatic intracerebral hemorrhages (ICH) after intravenous rt-PA $[1,6]$.

This review focuses on two main issues concerning the relationship between SVD and the effectiveness and safety of acute stroke thrombolytic treatment. In the first part, we review the literature concerning the question whether thrombolysis is efficacious in patients with acute lacunar stroke. In the second part, we summarize the existing ev- idence about the increased bleeding risk following thrombolysis in patients with concomitant SVD on neuroimaging. These points lead to the question whether or not patients with lacunar stroke or SVD should be treated with thrombolysis.

\section{Efficacy of Thrombolysis in Acute Lacunar Stroke}

Lacunar infarcts are small subcortical infarcts mainly located in the basal ganglia, internal capsule, thalamus, corona radiata and brainstem. On CT scans they appear as small hypodense areas. On MRI they are defined as foci of decreased signal on T1-weighted sequences and of increased signal on T2, DWI (diffusion-weighted imaging) and FLAIR (fluid-attenuated inversion recovery) located in the territory of 1 perforating arteriole and with a maximum diameter of about $20 \mathrm{~mm}$ in the axial plane (fig. 1). When symptomatic, they are associated with the classical Fisher lacunar syndromes, the most common of which are: pure motor hemiparesis, sensorimotor stroke, pure sensory stroke, dysarthria-clumsy-hand syndrome and ataxic hemiparesis [7]. Lacunar stroke accounts for about one fourth of the total cases of ischemic stroke, with incidence rates ranging from $13 / 100,000 /$ year up to $59 / 100,000 /$ year [8]. 
Table 1. Clinical studies investigating survival and functional outcomes in patients with lacunar stroke treated with intravenous thrombolysis compared with other stroke subtypes

\begin{tabular}{|c|c|c|c|c|c|c|}
\hline $\begin{array}{l}\text { Study and } \\
\text { year }\end{array}$ & Study design & Patient number & $\begin{array}{l}\text { Criterion definition } \\
\text { of lacunar stroke }\end{array}$ & Other stroke subtypes & $\begin{array}{l}\text { Major outcome } \\
\text { measures }\end{array}$ & Results \\
\hline $\begin{array}{l}\text { NINDS, } \\
1995 \text { [3] }\end{array}$ & $\begin{array}{l}\text { Randomized } \\
\text { multicenter } \\
\text { placebo-controlled }\end{array}$ & $\begin{array}{l}304(16.8)^{1} \\
302(9.9)^{2}\end{array}$ & $\begin{array}{l}\text { Baseline clinical } \\
\text { feature }\end{array}$ & $\begin{array}{l}\text { Large-vessel; } \\
\text { cardioembolic; } \\
\text { other }\end{array}$ & $\begin{array}{l}\text { NIHSS } \\
\text { mRS } \\
\text { BI } \\
\text { GOS }\end{array}$ & $\begin{array}{l}\text { Better outcome at } 3 \text { months } \\
\text { in lacunar stroke receiving } \\
\text { thrombolysis compared with } \\
\text { placebo }\end{array}$ \\
\hline $\begin{array}{l}\text { Hsia et al., } \\
2003 \text { [9] }\end{array}$ & $\begin{array}{l}\text { Retrospective } \\
\text { multicenter }\end{array}$ & $90(6.7)$ & $\begin{array}{l}\text { By TOAST } \\
\text { classification }\end{array}$ & $\begin{array}{l}\text { Large vessel; } \\
\text { cardioembolic; } \\
\text { other; } \\
\text { undetermined }\end{array}$ & $\begin{array}{l}\mathrm{mRS} \\
\mathrm{BI} \\
\mathrm{ICH} \text { rate }\end{array}$ & $\begin{array}{l}\text { Nonsignificant trend for better } \\
\text { outcome at } 3 \text { months in lacunar } \\
\text { stroke }\end{array}$ \\
\hline $\begin{array}{l}\text { Fluri et al., } \\
2010 \text { [10] }\end{array}$ & $\begin{array}{l}\text { Prospective } \\
\text { multicenter }\end{array}$ & $1,048(6.2)$ & $\begin{array}{l}\text { By TOAST } \\
\text { classification }\end{array}$ & $\begin{array}{l}\text { Large vessel; } \\
\text { cardioembolic; } \\
\text { other; } \\
\text { undetermined }\end{array}$ & $\begin{array}{l}\mathrm{mRS} \\
\mathrm{ICH} \text { rate }\end{array}$ & $\begin{array}{l}\text { Nonsignificant trend for better } \\
\text { outcome at } 3 \text { months in lacunar } \\
\text { stroke }\end{array}$ \\
\hline $\begin{array}{l}\text { Fuentes } \\
\text { et al., } \\
2012[12]\end{array}$ & $\begin{array}{l}\text { Prospective } \\
\text { multicenter }\end{array}$ & $1,479(4.1)$ & By ICD-10 & $\begin{array}{l}\text { Large vessel; } \\
\text { cardioembolic; } \\
\text { other; } \\
\text { unknown/multiple }\end{array}$ & $\begin{array}{l}\text { NIHSS } \\
\text { mRS }\end{array}$ & $\begin{array}{l}\text { Nonsignificant trend for worse } \\
\text { outcome at } 3 \text { months in lacunar } \\
\text { stroke }\end{array}$ \\
\hline $\begin{array}{l}\text { IST-3, } \\
2012[5]\end{array}$ & $\begin{array}{l}\text { Randomized } \\
\text { multicenter } \\
\text { open-treatment }\end{array}$ & $\begin{array}{l}1,513(11.1)^{1} \\
1,515(10.8)^{2}\end{array}$ & $\begin{array}{l}\text { Baseline clinical } \\
\text { feature }\end{array}$ & $\begin{array}{l}\text { Total anterior; } \\
\text { partial anterior; } \\
\text { posterior }\end{array}$ & $\begin{array}{l}\text { OHS } \\
\text { ICH rate }\end{array}$ & $\begin{array}{l}\text { Nonsignificant trend for worse } \\
\text { outcome at } 3 \text { months in lacunar } \\
\text { stroke receiving thrombolysis } \\
\text { compared with placebo }\end{array}$ \\
\hline $\begin{array}{l}\text { Shobha } \\
\text { et al., } \\
2013 \text { [13] }\end{array}$ & $\begin{array}{l}\text { Retrospective } \\
\text { case-cohort }\end{array}$ & $\begin{array}{l}1,630(12.0)^{1} \\
9,873(20.3)^{2}\end{array}$ & $\begin{array}{l}\text { By OCSP } \\
\text { classification }\end{array}$ & $\begin{array}{l}\text { Partial anterior; } \\
\text { total anterior; } \\
\text { posterior }\end{array}$ & $\begin{array}{l}\mathrm{mRS} \\
\text { discharge home } \\
\mathrm{ICH} \text { rate }\end{array}$ & $\begin{array}{l}\text { Better outcome at } 3 \text { months in } \\
\text { lacunar stroke receiving throm- } \\
\text { bolysis compared with placebo }\end{array}$ \\
\hline
\end{tabular}

Thrombolytic treatment for acute ischemic lacunar stroke has been debated for two main reasons. First, among all ischemic stroke subtypes, lacunar strokes are considered the most benign, frequently with favorable recovery. Second, given the underlying pathological process, mainly represented by lipohyalinosis, and the absence of a clear demonstration of thrombosis in lacunar infarcts, lacunar strokes may be not susceptible to pharmacological reperfusion theoretically based on thrombolysis.

The issue has been investigated in a number of series of acute stroke patients (table 1). The studies reviewed can be divided into two types: (1) those in which patients with lacunar stroke and treated with rt-PA were compared with lacunar stroke patients receiving placebo, and
(2) those in which a comparison was made among different stroke subtype patients treated with rt-PA.

In 1995, the NINDS (National Institute of Neurological Disorders and Stroke) trial showed a consistent benefit of intravenous thrombolytic treatment on functional outcome measures such as the Barthel index, modified Rankin Scale (mRS), Glasgow Outcome Scale and NIHSS (National Institutes of Health Stroke Scale) in the 606 patients enrolled. This positive effect was confirmed across all stroke subtypes, including small vessel occlusive strokes. The diagnosis of stroke subtypes was based on available information obtained before treatment was started [3].

In 2003, Hsia et al. [9] retrospectively analyzed the efficacy of intravenous thrombolysis in different stroke 
subtypes among 90 treated acute stroke patients. In this study, the stroke subtype diagnosis relied on the TOAST (Trial of Org 10172 in Acute Stroke Treatment) classification based on clinical presentation and complete diagnostic workup. A trend for better functional outcomes was found for lacunar strokes compared with cardioembolic and large artery stroke subtypes, and for fewer hemorrhagic complications and deaths. Unfortunately, the number of patients with lacunar strokes was very small (7 patients), so no definite conclusions could be drawn.

In a prospective Swiss study, the safety and efficacy of intravenous thrombolysis was analyzed in 65 acute stroke patients of presumed lacunar type [10]. Small artery occlusive disease was defined as the presence of a lacunar syndrome, neuroimaging findings consistent with a small lacunar infarction in the territory of basal or brainstem penetrating arteries, and the absence of stenoocclusive diseases of the parent artery or a cardioembolic disease. When compared with other stroke mechanisms, lacunar stroke patients died less often $(11.2$ vs. $1.5 \% ; p=0.014)$ and had more favorable functional outcome (mRS scores of $0-2$ in 58.9 vs. $75.4 \% ; \mathrm{p}=0.001$ ). This association was no further significant after correction for other possible confounders such as age, gender and baseline NIHSS score [10].

Data from the Helsinki Stroke Thrombolysis Registry demonstrated that 3 months after thrombolysis, patients with lacunar stroke $(\mathrm{n}=101 ; 11 \%$ of the whole study cohort) had a better prognosis compared with other stroke subtypes in terms of mortality and functional outcome [11]. Lacunar stroke turned out to be one of the independent predictors of good outcome [mRS score $\leq 2$; odds ratio, OR (95\% confidence interval, CI): 1.81 (1.01-3.23); $\mathrm{p}<$ $0.05]$, together with age, NIHSS score, glucose levels and absence of hyperdense artery sign on baseline CT [11].

Possible differences in early and delayed response to intravenous thrombolysis among different stroke subtypes have recently been analyzed in a prospective Spanish study as well [12]. No differences in NIHSS score improvement rate at $24 \mathrm{~h}$ after thrombolysis were found across patients with different etiological stroke subtypes, while, at day 7 , patients with lacunar stroke $(n=60 ; 4.1 \%)$ showed the least neurological improvement in terms of absolute NIHSS score reduction $(\mathrm{p}=0.02)$. At 3 months, the risk of a poor functional outcome ( $\mathrm{mRS}$ score $>2$ ) was significantly lower among lacunar strokes on univariate analysis [OR (95\% CI): 0.23 (0.11-0.50); p < 0.001], although no influence of stroke etiological subtypes was detected after adjustment for confounding factors. A poor outcome was independently associated with age, systolic blood pressure and baseline NIHSS score [12].
The IST-3 (Third International Stroke Trial) explored the efficacy and safety of intravenous rt-PA in patients aged $>18$ years affected by ischemic stroke within $6 \mathrm{~h}$ of symptom onset [5]. Lacunar strokes were similarly represented in the rt-PA group $(\mathrm{n}=168 ; 11.1 \%)$ and in the placebo group ( $\mathrm{n}=164 ; 10.8 \%)$. Also in this trial, no statistically significant difference was seen in terms of response to thrombolysis, as measured by the Oxford Handicap Scale, among different stroke subtypes [5].

According to a large prospective Canadian study, patients with lacunar stroke treated with rt-PA $(\mathrm{n}=195$; $12.0 \%$ ) had a better functional outcome at discharge compared with lacunar stroke patients not treated with rt-PA [ $\mathrm{n}=2,001 ; 88 \%$; for $\mathrm{mRS}$ scores $0-2$, relative risk, RR $(95 \%$ CI): 1.84 (1.59-2.13); for discharge to home, RR (95\% CI): 1.38 (1.19-1.60)] even after adjustment for confounding factors, while no benefits were detected in terms of mortality at 3 months [RR (50\% CI): 0.89 (0.54-1.47)] [13].

Overall, the above-reported data suggest that lacunar infarcts show a good clinical response to thrombolytic treatment and that there is currently no rationale for making an effort to identify this stroke subtype in order to exclude patients. Of note, data from the ECASS I (First European Cooperative Acute Stroke Study) indicated that a clinical presentation highly suggestive of lacunar syndrome combined with the absence of early ischemic changes on CT scans had a low positive predictive value for lacunar stroke, thus confirming that in acute settings it is difficult to accurately select different stroke subtypes on clinical grounds and on the basis of neuroimaging [14]. The use of MRI, albeit not frequently available today in the emergency room, could be of additional value in this regard.

\section{Thrombolysis-Related Bleeding Risk in Cerebral SVD}

Although intravenous thrombolysis is an effective and licensed treatment for acute ischemic stroke, ICH remains the most devastating and unpredictable complication related to this treatment. Symptomatic ICH occurs in about $2.4-10 \%$ of cases within $24-36 \mathrm{~h}$ after thrombolysis [15], and the identification of possible predictors is one of the major challenges in stroke research. Neuroimaging evidence of SVD is nowadays recognized as one of the risk factors for thrombolysis-related ICH, together with age, early ischemic CT changes, high blood pressure, hyperglycemia, stroke severity and lesion volume [16].

It should be noted that not all the symptomatic ICH in stroke patients treated with thrombolysis are due to hemorrhagic transformation of the acute infarct; in fact, the 

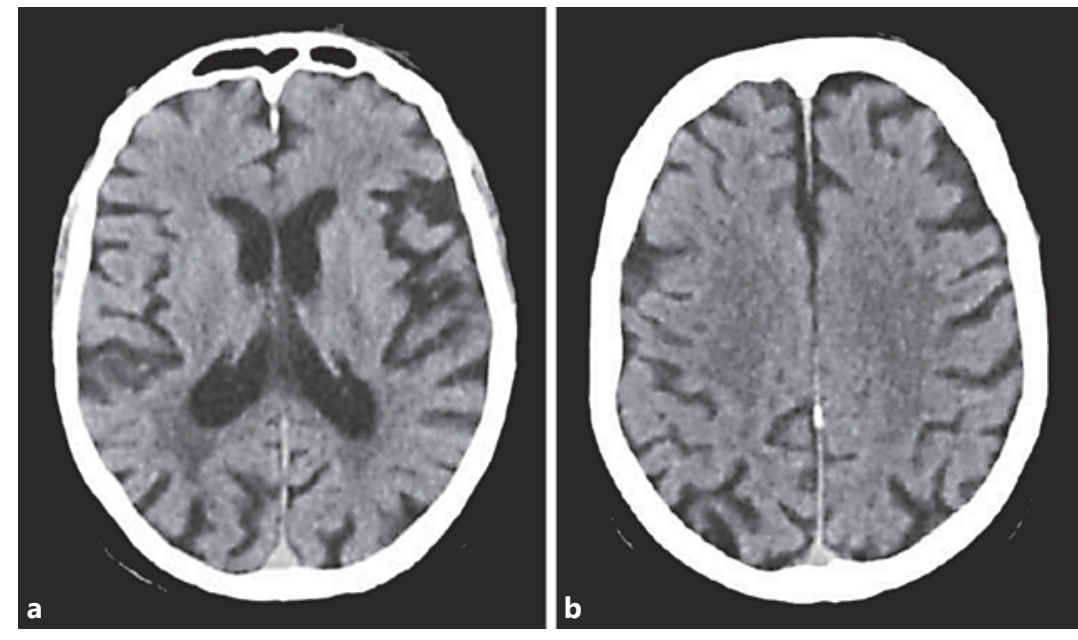

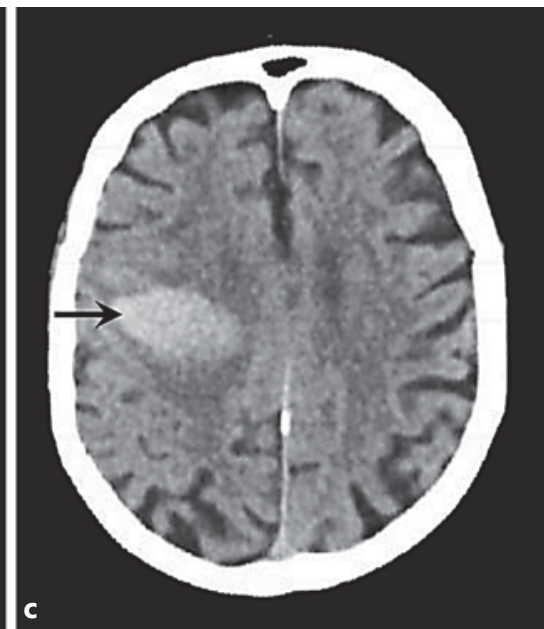

Fig. 2. Example of ICH after systemic thrombolysis possibly related to SVD. a, b Baseline CT scans of a 83-year-old man with slight weakness of the right hand and moderate aphasia (NIHSS score 3 ) treated with intravenous thrombolysis. Diffuse hypodensity of the subcortical white matter in both cerebral hemispheres.
After 55 min of rt-PA infusion, the patient suddenly developed coma followed by generalized tonic-clonic seizures with conjugate eye deviation to the right. c CT scanning performed soon after the stop of thrombolysis, showing an ICH (arrow) located in the right frontal lobe. bleeding site is sometimes distinct from the infarct area, a situation referred to as 'remote cerebral hemorrhage' [17]. There are, in fact, reports of symptomatic ICH in patients treated with thrombolysis for reasons other than stroke. In 1992, Leblanc et al. [18] described the case of a patient treated with thrombolysis for acute myocardial infarction who developed sudden neurological disturbances secondary to ICH; this side effect was possibly imputed to concomitant cerebral amyloid angiopathy. Figure 2 shows an example of a remote cerebral hemorrhage after thrombolysis for acute ischemic stroke in a patient with SVD.

The existence of a bleeding diathesis in patients with cerebral SVD is also supported by some data derived from scenarios different from the acute stroke setting. First of all, the natural history of SVD is characterized by an increased risk of ICH, as suggested by a first study published more than 20 years ago [19]. Second, a higher rate of ICH has been observed in patients with cerebral microbleeds and treated with aspirin [20] and in patients with leukoaraiosis treated with oral anticoagulants in comparison with those without leukoaraiosis [21-23].

Available evidence related to the risk of ICH in acute ischemic stroke series of patients treated with rt-PA points to a clear role for cerebral SVD (table 2). In this context, the 2 neuroimaging correlates of cerebral SVD that have mostly been taken into account are white matter lesions (WML) and microbleeds. One of the first clinical retrospective analyses was related to 449 patients with acute anterior circulation ischemic stroke treated with thrombolysis within $6 \mathrm{~h}$ from onset [24]. Leukoaraiosis was assessed by means of MRI and classified according to the Fazekas scale. The rate of symptomatic ICH was significantly higher in patients with moderate-to-severe leukoaraiosis in deep white matter compared with those with no or mild leukoaraiosis [ 10.5 vs. 3.8\%, respectively; OR ( $95 \%$ CI): 2.9 (1.29-6.59)]. The effect of moderate-to-severe leukoaraiosis was maintained after correction for confounders such as age, stroke severity and type of thrombolytic treatment (intravenous, intraarterial and combined) [24].

Confirmatory data come from a study in which the baseline CT scans of 936 acute ischemic stroke patients belonging to the CASES (Canadian Alteplase for Stroke Effectiveness Study) cohort were retrospectively reviewed [25]. The presence and extent of leukoaraiosis was assessed using the scale by van Swieten et al. [26]. This is a visual rating scale separately assessing the anterior and posterior regions of an axial brain CT scan on a 3-point scale from 0 ('no white matter hypodensity') to 2 ('confluent white matter hypodensity from the ventricles to the gray matter'). The original total score, obtained by summing the two scores in the anterior and posterior regions, ranges from 0 to 4 . In this study, the authors used a modified version of the scale as scores for the right and left hemispheres were summed (score range: $0-8$ ). A significantly higher risk of symptomatic ICH was observed in patients with severe leukoaraiosis (defined as a van Swi- 
Table 2. Clinical studies investigating the risk of ICH in patients with leukoaraiosis treated with thrombolysis

\begin{tabular}{|c|c|c|c|c|c|c|}
\hline $\begin{array}{l}\text { Palumbo et al., } \\
2007 \text { [25] }\end{array}$ & $\begin{array}{l}\text { Retrospective } \\
\text { multicenter }\end{array}$ & $936(-)$ & $\begin{array}{l}\text { By van Swieten } \\
\text { scale }\end{array}$ & IV rt-PA & $\begin{array}{l}\text { ICH with any } \\
\text { neurological } \\
\text { deterioration }\end{array}$ & $\begin{array}{l}\text { Higher rate of symptomatic ICH in } \\
\text { patients with severe } \\
\text { leukoaraiosis }\end{array}$ \\
\hline $\begin{array}{l}\text { Demchuk et al., } \\
2008 \text { [6] }\end{array}$ & $\begin{array}{l}\text { Retrospective } \\
\text { multicenter }\end{array}$ & $\begin{array}{l}299(33.1)^{1} \\
304(33.2)^{2}\end{array}$ & $\begin{array}{l}\text { By van Swieten } \\
\text { scale }\end{array}$ & IV rt-PA; placebo & $\begin{array}{l}\text { ICH with any } \\
\text { neurological } \\
\text { deterioration }\end{array}$ & $\begin{array}{l}\text { Nonsignificant trend for higher rate of } \\
\text { symptomatic ICH in patients with } \\
\text { leukoaraiosis receiving thrombolysis } \\
\text { compared with placebo }\end{array}$ \\
\hline $\begin{array}{l}\text { Ariës et al., } \\
2010 \text { [27] }\end{array}$ & $\begin{array}{l}\text { Retrospective } \\
\text { single center }\end{array}$ & $400(24.3)$ & $\begin{array}{l}\text { By van Swieten } \\
\text { scale }\end{array}$ & IV rt-PA & $\begin{array}{l}\mathrm{PH} 2 \text { with worsening } \\
\text { by } \geq 4 \text { points on } \\
\text { NIHSS or death }\end{array}$ & $\begin{array}{l}\text { Nonsignificant trend for higher rate of } \\
\text { symptomatic ICH in patients with } \\
\text { leukoaraiosis }\end{array}$ \\
\hline
\end{tabular}

eten score $>4$ ) compared with patients with no or moderate leukoaraiosis [8.4 vs. 3.0\%, respectively; RR (95\% CI): 2.75 (1.15-6.53)]. In this study, an important piece of information relates to the analysis concerning the predictive value of the number of lacunar infarcts. Patients with multiple lacunae, compared with those with no or only 1 , were at higher risk of symptomatic ICH [10 vs. $2.9 \%$, respectively; RR (95\% CI): 3.40 (1.50-7.68)], as well as of mortality at 3 months [OR (95\% CI): 2.9 (1.3-6.2)] [25].

Data from the NINDS rt-PA Stroke Study showed that the risk of symptomatic ICH was increased in both patients treated with rt-PA and those treated with placebo with higher leukoaraiosis severity degrees [6]. In patients with the most severe degree of leukoaraiosis, the absolute risk of symptomatic ICH was higher among the treated group when compared with the placebo (14.3 vs. $4.4 \%$ ), but this difference was below the limit of statistical significance because numbers were extremely limited [6]. However, the 3-month functional outcome expressed by the mRS did not differ greatly depending on the leukoaraiosis severity measured with the van Swieten scale [6]. Despite the fact that the small number of included patients with severe leukoaraiosis $(\mathrm{n}=72)$ represented a statistical limitation, these findings showed that the presence of leukoaraiosis on baseline neuroimaging is not critical to thrombolysis decision making in the first $3 \mathrm{~h}$ from symptom onset, and that the 3-month functional outcome is globally positive for lacunar stroke, leading to the conclusion that thrombolysis is certainly of some benefit in this kind of patients.

A Belgian study, analyzing data on 400 consecutive ischemic stroke patients receiving rt-PA, confirmed that the presence of leukoaraiosis, defined according to a van Swieten scale degree of $>0$, was associated with higher occurrence of symptomatic ICH (11\% in patients with leukoaraiosis vs. $4 \%$ in patients without) [27]. This association lost significance after correction for other potential confounders (such as antiplatelet therapy, age, NIHSS score, early ischemic changes, serum glucose level, hypertension, smoking, hyperlipidemia, gender, atrial fibrillation and previous stroke/transient ischemic attack), and in the final regression model, only baseline NIHSS score and prior antiplatelet drugs turned out to be the independent predictors of such a complication [27]. In the same study, the presence of leukoaraiosis was associated with worse functional outcome (mRS scores 3-6) even after correction for confounding factors [OR (95\% CI): 2.39 (1.21-4.72); $\mathrm{p}=0.01]$, confirming the known role of SVD as an independent risk factor for disability, cognitive impairment, dementia and depressive mood [28]. 
Table 3. Clinical studies investigating the risk of $\mathrm{ICH}$ in patients with cerebral microbleeds treated with thrombolysis

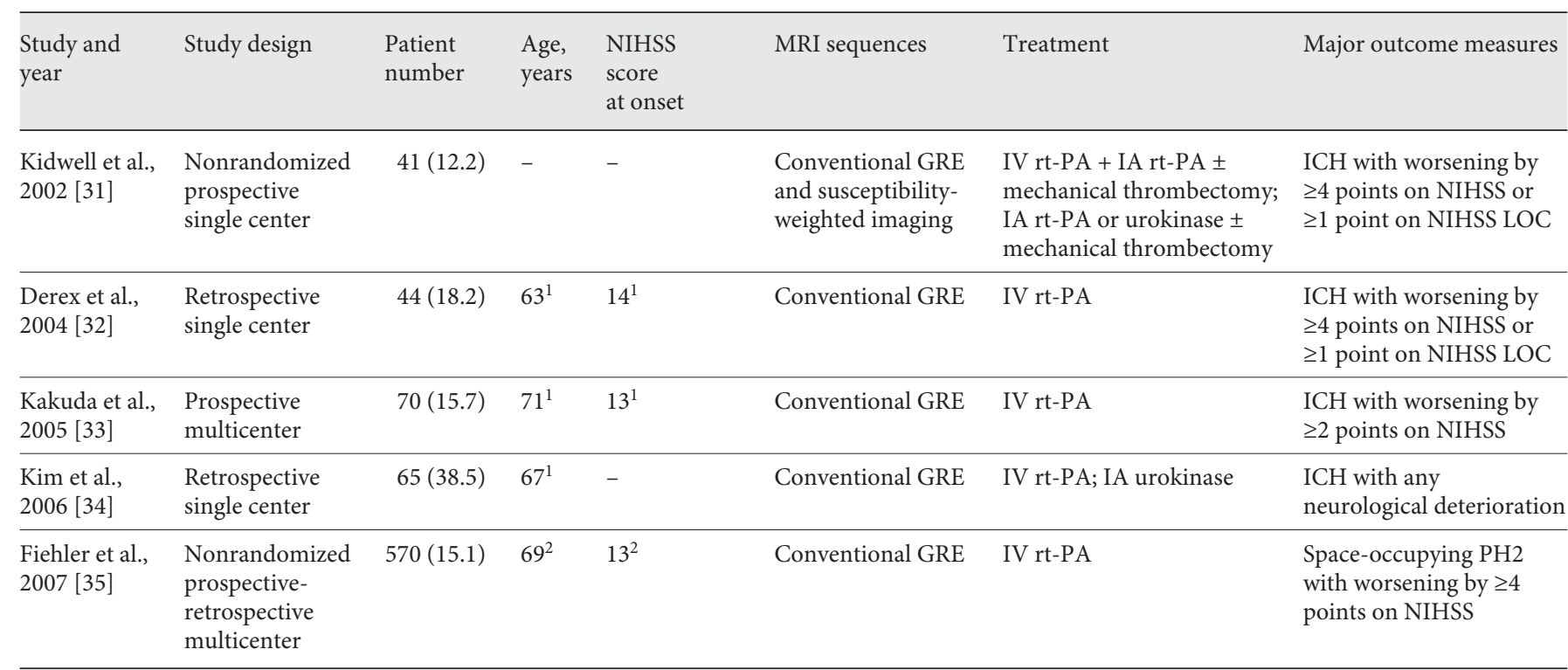

Values in parentheses denote \% cerebral microbleeds. GRE = Gradient-echo imaging; IV = intravenous; IA = intraarterial; LOC = level of consciousness; $\mathrm{PH} 2$ = parenchymal hematoma type 2 .

${ }^{1}$ Mean value.

${ }^{2}$ Median value.

The possible role of the presence of silent brain infarcts as a prognosis modifier in stroke patients receiving thrombolysis has been evaluated by Kobayashi et al. [29]. Among patients with a first-ever ischemic stroke, silent infarcts were detected in $46.9 \%$ of the baseline CT scans, being mostly represented by lacunar infarcts. No significant differences were found between patients with silent brain infarcts and those without in the ratio of 3-month mortality (24.7 vs. $15.1 \%)$, 3 -month death or disability (50.6 vs. $40.9 \%$ ) and ICH (18.3 vs. $14.0 \%$ ). Similarly, 3-month functional outcomes were not statistically different between patients with silent infarcts and accompanying WML and those with isolated silent infarcts (35.5 vs. 18.0\%) [29].

Recently, Shi et al. [30] investigated the relationship between the presence of leukoaraiosis on baseline MRI and the risk of intracranial bleeding in 105 large vessel stroke patients who underwent mechanical intraarterial thrombectomy. They found that patients with moderate or severe leukoaraiosis (Fazekas scores 2 and 3), compared with those with no or mild leukoaraiosis (Fazekas scores 0 and 1), presented higher rates of any hemorrhagic transformation ( 65.4 vs. $41.8 \%$; $\mathrm{p}=0.04)$ and in particular of parenchymal hematoma (42.3 vs. $19.0 \%$; $\mathrm{p}=$ 0.03 ), while similar frequencies of hemorrhagic infarcts and subarachnoid hemorrhage were detected [30].

Thrombolysis in Acute Stroke Patients with Cerebral SVD
Another neuroimaging correlate of SVD that has been taken into account in relation to the risk of ICH is microbleeds. Five studies [31-35] including a total of 790 acute ischemic stroke patients were pooled in a recent meta-analysis [36] with the aim of assessing the risk of $\mathrm{ICH}$ after thrombolysis in individuals with cerebral microbleeds on pretreatment MRI scans (table 3). A nonsignificant trend for a higher risk of symptomatic ICH was found in patients with microbleeds when compared with those without [RR (95\% CI): 1.90 (0.92-3.93); $\mathrm{p}=$ 0.082] [36]. Similar conclusions were drawn in another recent meta-analysis, based on the same studies, showing that the rate of symptomatic ICH was higher in patients with microbleeds on neuroimaging than in those without [OR (95\% CI): 1.98 (0.90-4.35); p = 0.09] [37]. Furthermore, a significant relationship was found between increasing microbleed number and risk of developing any ICH $(\mathrm{p}<0.0001)$ and symptomatic ICH $(\mathrm{p}=0.0015)$, introducing the concept of cerebral microbleed burden as a possible predictor of postthrombolytic intracranial bleeding. This risk was most evident in patients with $>10$ microbleeds, who experienced any ICH in $57 \%$ of cases [OR (95\% CI): 7.41 (1.51-36.4); $\mathrm{p}=0.01$ ] and symptomatic ICH in $29 \%$ of cases [OR (95\% CI): 12.18 (1.67-88.7); $\mathrm{p}=0.01]$ [37]. 
One first question, arising from the above data, could be: how many patients should we exclude from thrombolysis, assuming that cerebral microbleeds represent a contraindication to this treatment? Since the prevalence of microbleeds among acute ischemic stroke patients is about $33.5 \%$ [38], many patients would no longer be candidates for thrombolysis. A second question relates to the feasibility of detecting microbleeds in the emergency room, i.e. how could we identify these patients by means of CT scanning? Cerebral microbleeds are detected only by gradientecho MRI, but unfortunately MRI is infrequently available in the emergency room. In this regard, a prospective study evaluated whether the presence of microbleeds could be predicted from the extent of leukoaraiosis on CT [39]. It was found that microbleeds were more common with increasing degrees of leukoaraiosis on CT $(\mathrm{p}<0.001)$, but a high proportion of patients without WML had microbleeds and many patients with WML did not have microbleeds, implying that the presence of leukoaraiosis on pretreatment CT scans could not be used as a surrogate for the presence of cerebral microbleeds [39]. Moreover, even when MRI is available, it should be noted that several structures may resemble microbleeds, appearing as hypointensities on gradient-echo MRI, such as cerebral calcifications and deoxygenated blood in small veins [38], and therefore the selection could be more demanding.

\section{Conclusions}

From the above-reported literature we can conclude that lacunar strokes benefit from thrombolysis to a similar degree as the other stroke subtypes. This seems important because lacunar strokes were once considered the most benign subtype of stroke, with a frequently good recovery and a relatively small risk of early recurrence. In the long run, however, an excess risk of death, disability, stroke recurrence and cognitive impairment has been consistently documented [40]. We can also conclude that the presence of SVD on pretreatment neuroimaging confers an increased risk of both remote cerebral hemorrhage and hemorrhagic transformation of the infarcted area, but does not represent an absolute contraindication to thrombolysis. Thus, no overt evidence is currently available in favor of the exclusion of SVD patients from thrombolytic treatment when the accepted inclusion criteria are fully met.

For clinicians and researchers it could be useful to keep in mind that the spectrum of cerebral SVD is evolving. Since 2010, the recognized neuroimaging features of SVD have been cerebral microbleeds, parenchymal hematomas, leukoaraiosis and lacunar infarcts [1]. Currently, new radiological correlates of SVD are proposed by a large multidisciplinary group, including entities such as perivascular spaces and brain atrophy [2]. This promises to open new avenues for research on SVD, while the consequences in terms of management of stroke patients to be subjected to thrombolysis remain unpredictable at present.

In the future, a better quantitative definition of cerebral SVD could lead to a chart of risk stratification for acute stroke patients. Because of the limitation of CT in this sense, the achievement of this goal cannot disregard the use of MRI.

\section{Disclosure Statement}

L.P. is a member of the editorial boards of Acta Neurologica Scandinavica and Cerebrovascular Diseases. He is section editor ('vascular cognitive impairment') of Stroke. F.F. and A.P. report no conflict of interest.

\section{References}

1 Pantoni L: Cerebral small vessel disease: from pathogenesis and clinical characteristics to therapeutic challenges. Lancet Neurol 2010;9: 689-701.

2 Wardlaw JM, Smith EE, Biessels GJ, Cordonnier C, Fazekas F, Frayne R, Lindley RI, O'Brien JT, Barkhof F, Benavente OR, Black SE, Brayne C, Breteler M, Chabriat H, DeCarli C, de Leeuw FE, Doubal F, Duering M, Fox NC, Greenberg S, Hachinski V, Kilimann I, Mok, van Oostenbrugge R, Pantoni L, Speck O, Stephan BCM, Teipel S, Viswanathan A, Werring D, Chen C, Smith C, van Buchem M, Norrving B, Gorelick PB, Dichgans M, Stan- dards for Reporting Vascular Changes on Neuroimaging (STRIVE v1): Neuroimaging standards for research into small vessel disease and its contribution to ageing and neurodegeneration. Lancet Neurol 2013;12:822-838.

3 National Institute of Neurological Disorders and Stroke rt-PA Stroke Study Group: Tissue plasminogen activator for acute ischemic stroke. N Engl J Med 1995;333:1581-1587.

4 Hacke W, Kaste M, Bluhmki E, Brozman M, Dávalos A, Guidetti D, Larrue V, Lees KR, Medeghri Z, Machnig T, Schneider D, von Kummer R, Wahlgren N, Toni D; ECASS Investigators: Thrombolysis with alteplase 3 to
4.5 hours after acute ischemic stroke. N Engl J Med 2008;359:1317-1329.

5 IST-3 Collaborative Group, Sandercock P, Wardlaw JM, Lindley RI, Dennis M, Cohen G, Murray G, Innes K, Venables G, Czlonkowska A, Kobayashi A, Ricci S, Murray V, Berge E, Slot KB, Hankey GJ, Correia M, Peeters A, Matz K, Lyrer P, Gubitz G, Phillips SJ, Arauz A: The benefits and harms of intravenous thrombolysis with recombinant tissue plasminogen activator within $6 \mathrm{~h}$ of acute ischaemic stroke (the Third International Stroke Trial [IST-3]): a randomised controlled trial. Lancet 2012;379:2352-2363. 
6 6 Demchuk AM, Khan F, Hill MD, Barber PA, Silver B, Patel S, Levine SR, NINDS rt-PA Stroke Study Group: Importance of leukoaraiosis on CT for tissue plasminogen activator decision making: evaluation of the NINDS rtPA Stroke Study. Cerebrovasc Dis 2008;26: 120-125.

7 Fisher CM: Lacunar stroke and infarcts: a review. Neurology 1982;32:871-876.

$\checkmark 8$ Sacco S, Marini C, Totaro R, Russo T, Cerone $\mathrm{D}$, Carolei A: A population-based study of the incidence and prognosis of lacunar stroke. Neurology 2006;66:1335-1338.

-9 Hsia AW, Sachdev HS, Tomlinson J, Hamilton SA, Tong DC: Efficacy of IV tissue plasminogen activator in acute stroke: does stroke subtype really matter? Neurology 2003;61:71-75.

10 Fluri F, Hatz F, Rutgers MP, Georgiadis D, Sekoranja L, Schwegler G, Sarikaya H, Weder B, Müller F, Lüthy R, Arnold M, Reichhart M, Mattle HP, Tettenborn B, Nedeltchev K, Hungerbühler HJ, Sztajzel R, Baumgartner RW, Michel P, Lyren PA, Engelter ST: Intravenous thrombolysis in patients with stroke attributable to small artery occlusion. Eur J Neurol 2010;17:1054-1060.

-11 Mustanoja S, Meretoja A, Putaala J, Viitanen V, Curtze S, Atula S, Artto V, Häppölä O, Kaste M, Helsinki Stroke Thrombolysis Registry Group: Outcome by stroke etiology in patients receiving thrombolytic treatment: descriptive subtype analysis. Stroke 2011;42:102-106.

-12 Fuentes B, Martínez-Sánchez P, Alonso de Leciñana M, Egido J, Reig-Roselló G, DíazOtero F, Sánchez V, Simal P, Ximenez-Carrillo A, García-Pastor A, Ruiz-Ares G, GarcíaGarcía A, Masjuan J, Vivancos-Mora J, GilNuñez A, Díez-Tejedor E, Madrid Stroke Network: Efficacy of intravenous thrombolysis according to stroke subtypes: the Madrid Stroke Network data. Eur J Neurol 2012;19: 1568-1574.

13 Shobha N, Fang J, Hill MD: Do lacunar strokes benefit from thrombolysis? Evidence from the Registry of the Canadian Stroke Network. Int J Stroke 2013;8(suppl A100):45-49.

14 Toni D, Iweins F, von Kummer N, Busse O, Bogousslavsky J, Falcou A, Lesaffre E, Lenzi GL, ECASS I Group: Identification of lacunar infarcts before thrombolysis in the ECASS I study. Neurology 2000;54:684-688.

15 Derex L, Nighoghossian N: Intracerebral haemorrhage after thrombolysis for acute ischaemic stroke: an update. J Neurol Neurosurg Psychiatry 2008;79:1093-1099.

16 Álvarez-Sabín J, Maisterra O, Santamarina E, Kase C: Factors influencing haemorrhagic transformation in ischaemic stroke. Lancet Neurol 2013;12:689-705.

17 National Institute of Neurological Disorders and Stroke t-PA Stroke Study Group: Intracerebral hemorrhage after intravenous t-PA therapy for ischemic stroke. Stroke 1997;28: 2109-2118.
8 Leblanc R, Haddad G, Robitaille Y: Cerebral hemorrhage from amyloid angiopathy and coronary thrombolysis. Neurosurgery 1992; 31:586-590.

19 Inzitari D, Giordano GP, Ancona AL, Pracucci G, Mascalchi M, Amaducci L: Leukoaraiosis, intracerebral hemorrhage, and arterial hypertension. Stroke 1990;21:1419-1423.

20 Wong KS, Chan YL, Liu JY, Gao S, Lam WW: Asymptomatic microbleeds as a risk factor for aspirin-associated intracerebral hemorrhages. Neurology 2003;60:511-513.

21 Stroke Prevention in Reversible Ischemia Trial (SPIRIT) Study Group: A randomized trial of anticoagulants versus aspirin after cerebral ischemia of presumed arterial origin. Ann Neurol 1997;42:857-865.

22 Gorter JW: Major bleeding during anticoagulation after cerebral ischemia: patterns and risk factors. Stroke Prevention in Reversible Ischemia Trial (SPIRIT). European Atrial Fibrillation Trial (EAFT) study groups. Neurology 1999;53:1319-1327.

23 Smith EE, Rosand J, Knudsen KA, Hylek EM, Greenberg SM: Leukoaraiosis is associated with warfarin-related hemorrhage following ischemic stroke. Neurology 2002;59:193-197.

24 Neumann-Haefelin T, Hoelig S, Berkefeld J, Fiehler J, Gass A, Humpich M, Kastrup A, Kucinski T, Lecei O, Liebeskind DS, Rother J, Rosso C, Samson Y, Saver JL, Yan B, MR Stroke Group: Leukoaraiosis is a risk factor for symptomatic intracerebral hemorrhage after thrombolysis for acute stroke. Stroke 2006;37:2463-2466.

25 Palumbo V, Boulanger JM, Hill MD, Inzitari D, Buchan AM, CASES Investigators: Leukoaraiosis and intracerebral hemorrhage after thrombolysis in acute stroke. Neurology 2007;68:1020-1024.

26 van Swieten JC, Hijdra A, Koudstaal PJ, van Gijn J: Grading white matter lesions on CT and MRI: a simple scale. J Neurol Neurosurg Psychiatry 1990;53:1080-1083.

27 Ariës MJH, Uyttenboogaart M, Vroomen PC, de Keyser J, Luijckx GJ: tPA treatment for acute ischaemic stroke in patients with leukoaraiosis. Eur J Neurol 2010;17:866-870.

28 LADIS Study Group: 2001-2011: a decade of the LADIS (Leukoaraiosis and Disability) Study: what have we learned about white matter changes and small-vessel disease? Cerebrovasc Dis 2011;32:577-588.

29 Kobayashi A, Karlinski M, Litwin T, Czlonkowska A: Do silent infarcts modify the effect of thrombolysis for stroke? Acta Neurol Scand 2013;127:227-232.
30 Shi ZS, Loh Y, Liebeskind DS, Saver JL, Gonzalez NR, Tateshima S, Jahan R, Feng L, Vespa PM, Starkman S, Salamon N, Villablance JP, Ali LK, Ovbiagele B, Kim D, Viñuela F, Duckwiler GR: Leukoaraiosis predicts parenchymal hematoma after mechanical thrombectomy in acute ischemic stroke. Stroke 2012; 43:1806-1811.

31 Kidwell CS, Saver JL, Villablanca JP, Duckwiler G, Fredieu A, Gough K, Leary MC, Starkman S, Gobin YP, Jahan R, Vespa P, Liebeskind DS, Alger JR, Vinuela F: Magnetic resonance imaging detection of microbleeds before thrombolysis: an emerging application. Stroke 2002;33:95-98.

-32 Derex L, Nighoghossian N, Hermier M, Adeleine P, Philippeau F, Honnorat J, Yilmaz H, Dardel P, Froment JC, Trouillas P: Thrombolysis for ischemic stroke in patients with old microbleeds on pretreatment MRI. Cerebrovasc Dis 2004;17:238-241.

-33 Kakuda W, Thijs VN, Lansberg MG, Bammer R, Wechsler L, Kemp S, Moseley ME, Marks MP, Albers GW, DEFUSE Investigators: Clinical importance of microbleeds in patients receiving IV thrombolysis. Neurology 2005;65:1175-1178.

34 Kim HS, Lee DH, Ryu CW, Lee JH, Choi CG, Kim SJ, Suh DC: Multiple cerebral microbleeds in hyperacute ischemic stroke: impact on prevalence and severity of early hemorrhagic transformation after thrombolytic treatment. AJR Am J Roentgenol 2006;186:1443-1449.

35 Fiehler J, Albers GW, Boulanger JM, Derex L, Gass A, Hjort N, Kim JS, Liebeskind DS, Neumann-Haefelin T, Pedraza S, Rother J, Rothwell P, Rovira A, Schellinger PD, Trenkler J, MR STROKE Group: Bleeding Risk Analysis in Stroke Imaging before Thrombolysis (BRASIL): pooled analysis of $2^{*}$-weighted magnetic resonance imaging data from 570 patients. Stroke 2007;38:2738-2744.

36 Charidimou A, Kakar P, Fox Z, Werring DJ: Cerebral microbleeds and the risk of intracerebral haemorrhage after thrombolysis for acute ischaemic stroke: systematic review and meta-analysis. J Neurol Neurosurg Psychiatry 2013;84:277-280.

37 Shoamanesh A, Kwok CS, Lim PA, Benavente OR: Postthrombolysis intracranial hemorrhage risk of cerebral microbleeds in acute stroke patients: a systematic review and metaanalysis. Int J Stroke 2013;8:348-356.

38 Cordonnier C, Al-Shahi Salman R, Wardlaw $\mathrm{J}$ : Spontaneous brain microbleeds: systematic review, subgroup analyses and standards for study design and reporting. Brain 2007;130: 1988-2003.

- 39 Görner A, Lemmens R, Schrooten M, Thijs V: Is leukoaraiosis on CT an accurate surrogate marker for the presence of microbleeds in acute stroke patients? J Neurol 2007;254:284289.

40 Norrving B: Long-term prognosis after lacunar infarction. Lancet Neurol 2003;2:238-245.
Thrombolysis in Acute Stroke Patients with Cerebral SVD
Cerebrovasc Dis 2014;37:5-13

DOI: $10.1159 / 000356796$ 